\title{
Climate sceptics switch focus to economics
}

Ron eports by the Intergovernmental Panel on Climate Change (IPCC) are held out as a model of consensus science, with thousands of international scientists coming together to present the most detailed look ever at a single scientific topic. Yet a consensus among most of the world's researchers does not mean that everybody agrees.

"I am one of the 2,000 with their names on [the assessment], but don't sign me up for that catastrophic view of climate change," says John Christy, a climatologist at the University of Alabama in Huntsville and a contributing author to the report.

And outside the IPCC process there remains a dwindling band of climate sceptics, those who argue that global warming is not linked to human activity and that it would be rash to take drastic action to cut carbon emissions. The focus of these arguments, however, has shifted noticeably since the previous IPCC report was published six years ago. Many of the scientific uncertainties the sceptics have seized on are no more.

"Their argument continues to shift," says Naomi Oreskes, a geologist and science historian at the University of California, San Diego.
"That makes it clear that the issue for them is not the science. Whatever the science is, they will try to find ways to question it."

The previous IPCC report, for instance, gained infamy for featuring in its summary for policymakers the 'hockey stick' palaeotemperature graph. This shows a sharp rise in temperatures at the end of the last millennium that forms the blade of the hockey stick. Sceptics, notably economist Ross McKitrick of the University of Guelph in Canada and minerals consultant Steven McIntyre, have spent years working to discredit the statistical analysis and temperature proxies that were used to create the graph.

But a host of other studies, including a 2006 review by the US National Academy of Sciences, has reaffirmed that the past decade has seen an unprecedented rise in global temperatures. "This is just one of many lines of evidence," Michael Mann of Pennsylvania State University in University Park told an audience of congressional aides in Washington DC last week. Mann is the originator of one version of the graph.

Another key argument for sceptics has been the apparent discrepancy between warming at Earth's surface and temperatures in Earth's lower atmosphere, which satellite records suggested have cooled over the past several decades. But in 2005, a major US report, commissioned specifically to look into this question, concluded that the original data had been

\section{What price a cooler future?}

Last year's review on climate change by Nicholas Stern, a senior British civil servant and former vice-president of the World Bank, was conceived as the definitive statement on the cost of climate change. So far, though, its legacy has been a debate among economists that has as much to do with ethics as money.

"The review and the critiques that have followed it highlight that many of the important questions boil down to what we choose to value," says Roger Pielke Jr, an expert in climate-change policy at the University of Colorado, Boulder. Perhaps the most vexing question is how current generations should value their successors' welfare.
The Stern report, published in October 2006, concluded that doing nothing about climate change would mean a long-term loss in

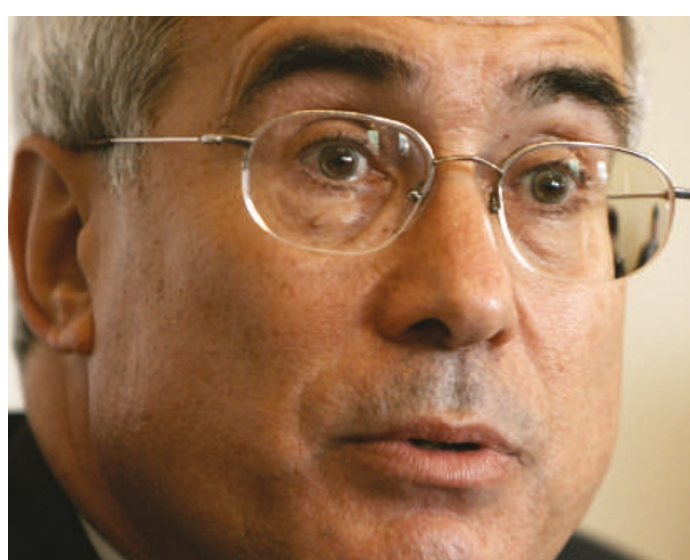

average world consumption of $5-20 \%$ per year, whereas stabilizing greenhouse-gas concentrations at roughly double pre-industrial

Nicholas Stern has been criticized for overestimating the current value of future generations' welfare. levels would cost $1 \%$ of global gross domestic product (GDP) by the middle of this century, with a margin of error of plus or minus $3 \%$.

These calculations depend partly on the value we in the present assign to money received or spent in the future - determined by discounting. To stop climate change, we are being asked to pay now and live later, but most people value future benefits less than current costs, and will only invest if the projected pay-off is large enough.

The contentious issue is the size of the 'pure-time' discount rate, which determines how much the the welfare of current generations is valued compared with future, as yet non-existent generations. 
The Sun has set on most scientific objections to the evidence for global warming. analysed incorrectly, and when corrected do indeed show a slight warming.

Other favourite arguments of climate sceptics are also dismantled in the latest IPCC report. Urban heat islands - the fact that cities tend to heat the air above them - do exist, the report says, but have a negligible effect on global temperatures. And solar variability natural fluctuations in the amount of the Sun's radiation reaching Earth - does affect climate, but to a far smaller extent than the burning of fossil fuels.

With less to argue about on the scientific front, climate sceptics have been turning their attention to the economics of adapting to a changing climate.

Christy believes that fostering innovation is the way to decrease reliance on fossil fuels.

"We're going to look back in a century and say 'wasn't it quaint, we burned carbon'" he says. "I'm very optimistic; I see the wealth of the Earth continuing to rise. But suppressing energy is not the way. Keep energy inexpensive and affordable and allow people to do research." As for the Kyoto Protocol on climate change, the international agreement to reduce carbon emissions, Christy calls it "sinister".

Economic arguments also play a strong role in the views of sceptic Patrick Michaels, an environmental scientist at the University of Virginia who argues that taking action on climate change can have dire economic consequences. He sees the current US move towards embracing biofuel as causing corn prices to surge, triggering inflation and leaving many poor people, particularly in Mexico, struggling to buy food. "Small changes in policy can lead to a recession," he says.

It remains to be seen whether these arguments will gain much traction. Alan Thorpe of Britain's Natural Environment Research Council, which hosted an online debate to canvass climate sceptics on their views, says that such views range from lazy to devious.

"I think there is a degree to which there is mischievous use of scepticism," he says. "Sceptics want to accuse scientific society of wanting a particular policy outcome, but actual policy is up to governments."

Michael Hopkin
The Stern review used a very low pure-time discount rate, treating current and future generations equally. But there is little consensus on this among economists. Some, such as William Nordhaus of Yale University in New Haven, Connecticut, find low rates hard to accept, adding that the way markets work supports this position.

Stern's conclusion "depends decisively on the assumption of a near-zero discount rate", Nordhaus wrote in a critique posted on his website in November. Nordhaus recalculated Stern's assessment of the optimal rate at which emissions should be reduced using a pure-time discount rate of $3 \%$ that declines to $1 \%$ in 300 years, rather than the $0.1 \%$ rate used in the Stern review. The change cut the optimal rate of emissions reduction by 2050 from $25 \%$ to $14 \%$. Stern retorts that a pure-time discount rate of $1 \%$ is "outrageously high", as it values things happening in 100 years as only one-third as important as things happening now.

Economist Partha Dasgupta of the University of Cambridge, UK, although largely supportive of Stern's conclusions, takes issue with the way that the report's egalitarian approach to different generations valuing their well-being equally - is not carried through to its discussion of inequalities in today's world. Stern's calculations, Dasgupta argues, understate the degree to which a given dollar benefits a poor person more than a rich one.

Such arguments may seem like a good way to stall progress, but many, including Stern, value the attention to ethics. "How important a problem climate change is and what society should do about it is all about subjective judgements," says Mike Hulme, director of the Tyndall Centre for Climate Change Research

"How important a problem climate change is and what society should do about it is all about subjective judgements."

\section{in Norwich, UK.}

However, the focus on the discount rate's effects on the estimated cost of damage has partly overshadowed the Stern report's second striking conclusion - that the worst effects of climate change can be avoided for at most $4 \%$ of GDP.
A few weeks after the main report's publication, the Stern review team released a sensitivity analysis that looked at how the conclusions might differ with more conservative estimates of damage costs derived from different value systems. Further analyses will be published in the next couple of weeks. These have shown that the conclusion that prevention will be much cheaper than dealing with the damage is fairly robust, given moderate changes in the parameters.

The debate about discount rates only looks at half the picture, says Ottmar Edenhofer, an economist at the Potsdam Institute for Climate Impact Research in Germany. Just as crucial is the debate about how to reduce emissions.

Lucy Odling-Smee 